\title{
Trombosis venosa cerebral
}

\author{
Cerebral venous thrombosis \\ Itzel Ariadna Hernández Dehesa, ${ }^{*}$ María de Guadalupe Gómez Pérez, ${ }^{\ddagger}$ Jaime Bravo Valle ${ }^{\S}$ \\ Citar como: Hernández DIA, Gómez PMG, Bravo VJ. Trombosis venosa cerebral. Acta Med \\ GA. 2021; 19 (4): 564-565. https://dx.doi.org/10.35366/102549
}

Femenino de 34 años de edad, antecedentes personales patológicos de síndrome de ovario poliquístico en tratamiento con anticonceptivos orales de larga evolución. Niega otras comorbilidades. Inicia su padecimiento actual con deterioro cognitivo de inicio súbito posterior a cefalea holocraneana pulsátil de intensidad moderada de 15 días de evolución, motivo por el cual acude a urgencias. A la exploración física los signos vitales se encontraban dentro de parámetros habituales. Se interconsulta al Servicio de Neurología, quien solicita resonancia magnética secuencia stroke con venorresonancia que reporta ausencia de señal del seno transverso y sigmoideo del lado izquierdo compatible con trombosis más infartos venosos de localización temporal y occipital asociado a edema perilesional (Figura 1A-D).
El seno sagital superior (SSS), seno lateral (SL) y los senos transversos son los sitios de localización de trombosis venosa cerebral (TVC) más frecuentes en orden decreciente. ${ }^{1} \mathrm{La}$ edad de presentación es entre 31 a 50 años, con predominio en el sexo femenino. Los factores de riesgo se clasifican en dos subgrupos: de origen local o de origen sistémico. ${ }^{2}$ Los pacientes en los que la TVC se desarrolla de forma aguda suelen presentar datos de focalización neurológica, mientras que en la forma crónica, la elevación aislada de la PIC es la forma más habitual de presentación. ${ }^{3}$

El hallazgo más sensible en cuanto a la tomografía simple es la visualización directa de la trombosis en el seno dural y dentro de los hallazgos inespecíficos pueden incluir edema cerebral difuso (20 a 50\%), disminución del tamaño ventricular y el infarto venoso; en la tomografía contrastada el signo delta
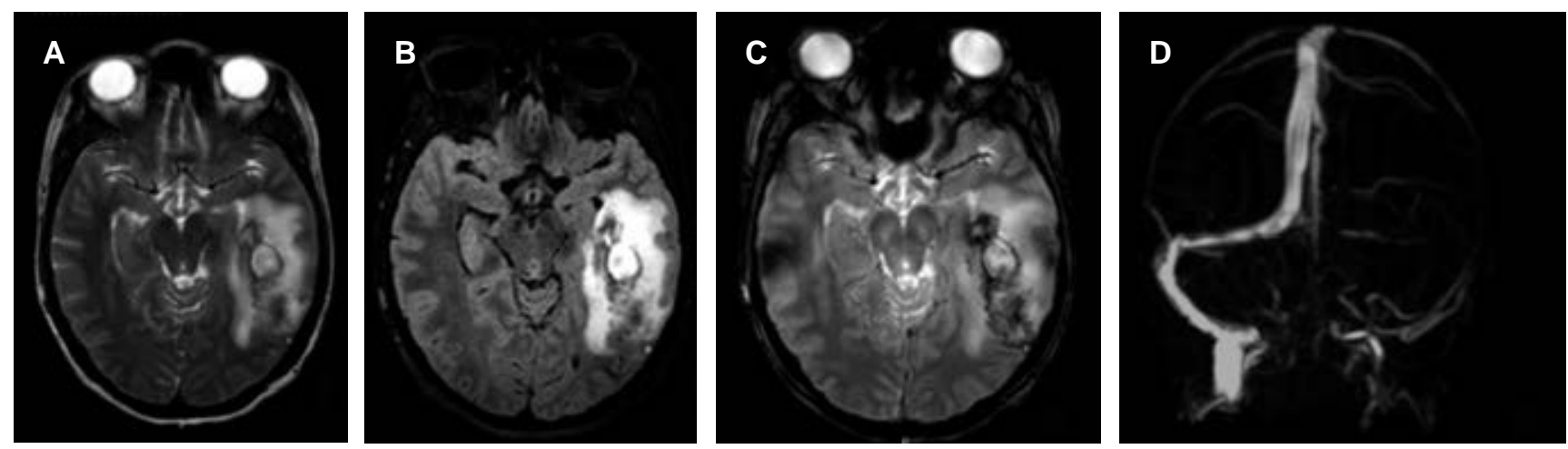

Figura 1: Resonancia magnética en secuencias potenciadas en: A) T2, B) FLAIR, C) hemogradiente, plano axial. Hiperintensidades de localización temporal y occipital con depósitos de hemosiderina y datos de edema perilesional en relación con infartos venosos. D) Venorresonancia. Ausencia de señal del seno transverso y sigmoideo izquierdo compatible con trombosis.

\footnotetext{
* Médico Radiólogo. Curso de Alta Especialidad en Resonancia Magnética Corporal, Hospital Angeles Pedregal.

₹ Médico Radiólogo. Profesora Titular del Curso de Alta Especialidad Resonancia Magnética Corporal y Musculoesquelético, Hospital Angeles Pedregal.

$\S$ Médico Neurorradiólogo. Hospital Angeles Pedregal.
}
Correspondencia:
Dra. Itzel Ariadna Hernández Dehesa
Correo electrónico: ariadnadehesahdez@hotmail.com Aceptado: 03-08-2020.
www.medigraphic.com/actamedica

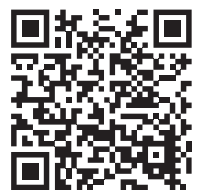


vacío es característico. Sin embargo, la resonancia magnética en combinación con la venografía es el método de imagen de elección donde observaremos cambios en el parénquima resultado de la oclusión venosa que incluyen edema cerebral y zonas de infarto venoso de tipo hemorrágico o no hemorrágico. ${ }^{4}$

\section{REFERENCIAS}

1. Leach JL, Fortuna RB, Jones BV, Gaskill-Shipley MF. Imaging of cerebral venous thrombosis: current techniques, spectrum of findings, and diagnostic pitfalls. v 26, University of Cincinnati College of Medicine, Ohio. 2016, S19-S41.

2. Guenther G, Arauz A. Trombosis venosa cerebral: aspectos actuales del diagnóstico y tratamiento, v 26, no. 8, Sociedad Española de Neurología. 2011, 488-498.

3. Ferro JM, Canhao P, Kasner SE, Goddeau RP Jr. Cerebral venous thrombosis: etiology, clinical features, and diagnosis. Biblioteca Nacional de Medicina, EUA, 2019, 1-3.

4. Miranda H, Mellado P, Sandoval P, Huete LI. Trombosis venosa cortical aislada: Comunicación de dos pacientes. Rev Méd Chile. 2007; 135: 1313-1317. 